in London, he was visibly disappointed. However, he also recommended immediately that I apply to train at the Royal Free Hospital, which he said he had visited the year before.

I remember him saying that he had been very impressed by the newly built mother and baby unit in the general ward, clearly another example of the type of innovation which he greatly admired.

Professor Cazzullo did not suffer fools gladly. He was a great inspirational figure and a towering giant in Italian psychiatry. He had enemies and friends like all those who make history. He was above all a moderniser. Psychiatrists whose lives and careers he helped to shape and who were touched by his incredible intellect will always miss him dearly.

Giuseppe Spoto

doi: 10.1192/pb.bp.110.032565

\section{Dr Ronald Arthur Sandison}

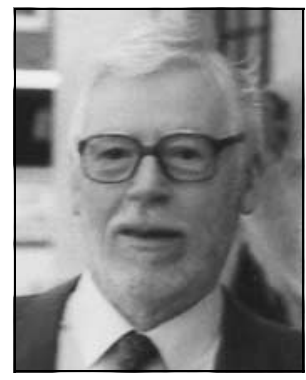

\section{Formerly Honorary Consultant, Southend, Ledbury}

Sandison was born in 1916, in the Shetland Isles 200 miles north of Scotland. He started his pre-clinical studies in 1934 and qualified MBBS (Lond) in 1940. During the war he served in the RAF as a physiologist studying altitude effects on Spitfire pilots. In 1945 he became a trainee psychiatrist at Warlingham Park Hospital, Surrey. There, fascinated by the dreams patients experienced during insulin coma therapy, he developed an interest in Jungian psychology.

Ronald moved to Powick Hospital in Worcestershire in 1951 as a consultant and began improving the dilapidated hospital. In 1952, while on a tour in Switzerland, he serendipitously visited the Sandoz laboratories and met Albert Hofmann, the discoverer of the experimental compound lysergic acid diethylamide (LSD). This remarkable drug is virtually inert physiologically, physically non-toxic and not addictive, yet immensely powerful at minute doses. Sandison was fascinated by what he saw and returned to the UK with 100 vials of the drug.

At this stage, LSD had only been used on a handful of people, but there was a growing theoretical basis for using it as an adjunct for psychotherapy. Impressed by LSD's effects on altering human consciousness, Sandison began using infrequent low doses with his patients 'stuck' in various stages of their psychoanalysis. He noticed immediate positive results, even in cases of severe, unremitting illness. The drug appeared to produce hallucinations of a dream-like quality, which directly reflected the patient's unconscious mind, allowing them to relive forgotten memories.
In 1954, the same year that Aldous Huxley published The Doors of Perception, Sandison published a paper with his colleagues Spencer and Whitelaw describing LSD-assisted psychotherapy on 36 patients in which the treatment was overwhelmingly positive and without adverse effects.

In 1955 he developed the world's first purpose-built LSD unit in the grounds of Powick, where up to five patients could receive LSD simultaneously, in rooms equipped with a couch, a chair and a blackboard for drawing emerging images.

Dr Sandison and his team oversaw the sessions and came together with the patients for a group session at the end of the day.

The Powick model became the blueprint used throughout Britain and the world for LSD treatment and, at this point in history, LSD was hoped to be 'the next big thing' in modern psychiatry. In 1955 Sandison addressed the American Psychiatric Association about his work. Then, in 1961, he chaired the Royal Medico-Psychological Association meeting, which was devoted entirely to LSD therapy.

In 1964, after 12 years dedicated to seeing thousands of patients through LSD psychotherapy, Sandison ended his work at Powick and took a job at Knowle hospital near Southampton. The drug was becoming misused widely outside the medical profession and, like many psychiatrists at the time, Sandison chose to distance himself from the growing negative media attention. Also frustrated by psychiatry's increasing dependence on daily-prescribed psychotropic drugs he found himself gravitating towards psychotherapy.

He joined the Group Analytic Society and, for the next 10 years, ran group therapy workshops, developed a therapeutic community and ran a day hospital. Dedicated to keeping psychotherapy firmly embedded in the National Health Service, he encouraged registrars to take a diploma in psychotherapy and recruited medical students to the newly formed Southampton Medical School.

Between 1975 and 1982, Sandison returned to his native Shetland and overhauled the threadbare psychiatric services there. For the remainder of his working life he used his psychotherapy skills in the field of psychosexual medicine and family planning at the Margaret Pyke centre in London, before retiring in 1992.

Despite his broad career, Ronald Sandison will be remembered worldwide for his pioneering work with LSD. He considered many psychiatric drugs to, at best, mask symptoms - in stark contrast to LSD, which, when used in a controlled environment, allowed material to be worked through with psychotherapy. He loathed the recreational use of drugs, preferring his own term 'psycholytic' ('mind-loosening') to the heavily popularised word 'psychedelic'.

He was a deeply compassionate doctor, not afraid to watchfully push the boundaries of tradition to explore potential new benefits for his patients. A true pioneer in medicine, he will be missed.

He died peacefully on 18 June 2010.

Ben Sessa

doi: 10.1192/pb.bp.110.032540 